\title{
Prevalence of Broken Denture in Completely Edentulous Patients - A Retrospective Study
}

Research Article

Prashaanthi. $\mathrm{N}^{1}$, Jessy. $\mathrm{P}^{2 *}$, Subhabrata Maiti ${ }^{3}$, Shantha sundari. K.K $\mathrm{K}^{4}$

${ }^{1}$ Saveetha Dental College and Hospitals, Saveetha Institute of Medical and Technical Sciences, Saveetha University, Chennai, India.

${ }^{2}$ Senior Lecturer, Department of Pedodontics, Saveetha Dental College and Hospitals, Saveetha Institute of Medical and Technical Sciences, Saveetha University, Chennai, 600077, India.

${ }^{3}$ Senior Lecturer, Department of Prosthodontics, Saveetha Dental College and Hospitals, Saveetha Institute of Medical and Technical Sciences, Saveetha University, Chennai, 600077, India.

${ }^{4}$ Professor, Department of Orthodontics, Saveetha Dental College and Hospitals, Saveetha Institute of Medical and Technical Sciences, Saveetha University, Chennai, 600077, India.

\section{Abstract}

Replacement of missing teeth and the associated structures are done with the help of artificial prosthesis. One of the most common complications of the denture is the fracture. There are numerous factors contributing to the fracture of denture. The aim of the study was to evaluate the prevalence of broken complete denture among completely edentulous patients. This retrospective study included patients who reported with complete edentulism from July 2019 to March 2020 in a dental hospital. The case records of all patients were retrieved and details were recorded. Variables such as age, gender, status of the denture whether fractured or not were also extracted from the case records. Data was tabulated and statistically analysed using IBM SPSS version 20.0 and results were obtained. Descriptive and chi square analysis was done to get the association among age, gender and the broken denture. $P$ value $<0.05$ was considered as statistically significant.In the present study, out of 355 completely edentulous patients , $8.2 \%$ reported with broken denture. On comparing the different age groups, there was higher prevalence among 51-60 years age groups $(5.07 \%)$. On analysing the prevalence of broken dentures among gender, $5.92 \%$ of males and $2.25 \%$ of females reported with broken dentures, with a higher prevalence among males. There was statistically significant association between age and broken denture $(p<0.05)$ and no statistically significant association was found between gender and the broken denture $(p>0.05)$. Within the limitations of the present study, there was higher prevalence of broken denture among males which could be due to high masticatory forces. And the broken dentures were more commonly reported among old aged population which could be due to long term usage of the denture.

Keywords: Denture Fracture; Mastication; Occlusal Prematurity; Porosity.

\section{Introduction}

The ideal treatment for completely edentulous patients is rehabilitation by conventional complete denture. The esthetics, mastication, speech are affected in a completely edentulous patient wherein there is a need for the construction of the complete denture. The factors causing problems in the complete denture fabrication and adaptation by the patients may be classified as adverse intraoral anatomical factors, clinical factors such as poor denture stability, technical factors such as failure to preserve the peripheral seal on a master cast and patient adaptional factors [1].

After the complete denture delivery, acceptance and wearing complete dentures is one of utmost important factors for the success of complete denture [2]. The patient's face various problems or interferences in wearing the denture. One of the interferences in wearing dentures is the fracture of the denture. Previous studies have reported that the most common complication of the denture is the denture fracture which leads to the discontinuity of denture wearing among patients [2].

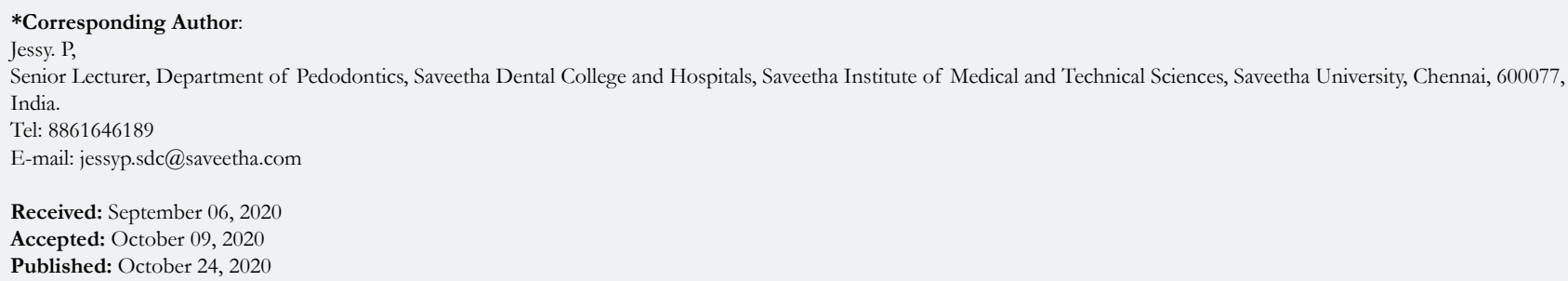

Copyright: Jessy. $\mathbf{P}^{\circ} 2020$. This is an open-access article distributed under the terms of the Creative Commons Attribution License, which permits unrestricted use, distribution and reproduction in any medium, provided the original author and source are credited. 
Denture fractures cause functional insufficiency, compromised esthetic and financial burden on its users for its repair or refabrication [3-5].

One of the reasons for the fracture of the denture could be the masticatory efficiency, bite and chewing efficiency of the patients which has an important role in the functional adaptation of prosthetic rehabilitation [6]. The relative measures for the preparation and adaptation to the swallowing capacity of the individual should be taken into consideration during the construction and fabrication of the denture [7-9].

Other factors that exacerbates the deformation of the base or alters its stress distribution are the polymethyl methacrylate dentures which are prone for fractures [10]. The challenges faced during the construction of the denture is the displacement of the denture during chewing and speaking [11]. Adequate follow up of the patients is one of the difficulties faced after the denture insertion. The selection of appropriate dental material and technique has an important role in the maintenance and success of the complete denture. Proper oral hygiene maintenance by the patient also has an essential role in the denture wearing patients [4].

Hence there should be adequate longer follow up in order to check whether the patient continued to wear denture or not and also to assess the status of the denture. If there is a fracture, the identification of the fracture on which part of the denture, whether on the denture base or on the artificial teeth has to be noted and further repair or rebasing should be carried out to replace the fractured denture among patients [1, 4]. Previously our institutional team has done various awareness studies [12-14], clinical studies [15-22] ,systematic reviews [21, 23-26]. Now we are focussing on epidemiological studies. The thought for this study stemmed from the present interest in our community.Hence the aim of this study was to assess the prevalence of completely edentulous patients reporting with broken denture.

\section{Materials and Methods}

\section{Study design and study setting}

This retrospective study was conducted to evaluate the patients reporting with broken dentures who visited Saveetha dental college and hospital from July 2019 to March 2020. The study was initiated after approval from the Institutional ethical committee. Ethical approval number was SDC/SIHEC/2020/DIASDATA/0619-0320.

\section{Sampling}

After thorough assessment of 86000 case records in the university patient data records, case records of all completely edentulous patients were included in the study. The exclusion criteria was missing or incomplete data. Cross verification of data for errors was done with the help of an external examiner.

\section{Data collection}

The case records of the completely edentuous patients from July 2019 to March 2020 were examined by a single calibrated examiner. Relevant factors such as status of the denture whether broken or not broken were retrieved. Demographic details such as age , gender were also recorded.

\section{Statistical analysis}

The collected data was tabulated and analysed with a statistical package for windows, IBM SPSS version 20.0 and results were obtained. Categorical variables were expressed in frequency and percentage. Chi Square tests were employed to analyse the association of categorical variables with a level of significance set at $\mathrm{p}<0.05$.

\section{Results and Discussion}

In our study, out of 355 completely edentulous patients, $8.2 \%$ of the patients reported with broken denture. On comparing the distribution percentage of broken dentures among different age groups it was found that $5.07 \%$ were under $51-60$ years, $2.25 \%$ were under $61-70$ years, $0.56 \%$ under $41-50$ years, $0.28 \%$ were under 31-40 years age groups. On analysing the association of broken dentures, the higher prevalence was found among 51-60 years $(5.07 \%)$ followed by the $61-70$ years age group $(2.3 \%)$. [Figure 1] There was a statistically significant association between the status of the dentures among different age groups. ( $p$ value-0.001) [Table 1, Figure 2]

In our study out of 355 completely edentulous patients , $57.92 \%$ were males and $41.97 \%$ were females. On analysing the association between the status of the dentures among gender, there was a higher prevalence among males (5.92\%) than females $(2.25 \%)$. [Figure 3] No statistically significant association was found between the status of the denture and gender.( $p$ value -0.101). [Table 1 , Figure 4]. The result of the study shows that the most affected

Figure 1. Bar graph shows the age wise distribution of patients with complete edentulism. $\mathrm{X}$ axis - age in years ; $\mathrm{Y}$ axis - number of patients with complete edentulism. The higher prevalence of complete edentulism was found among 51-60 years. $(37.18 \%)$

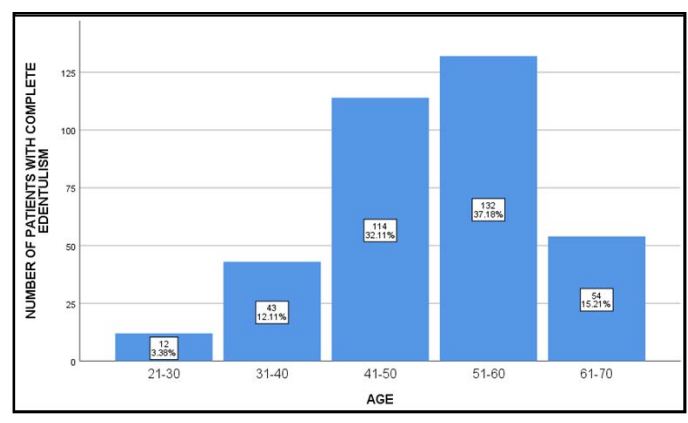


Table 1. The association of status of denture among different age groups and gender.

\begin{tabular}{|c|c|c|c|c|}
\hline Variables & $\begin{array}{l}\text { Status of den- } \\
\text { ture - Broken }\end{array}$ & $\begin{array}{c}\text { Status of denture- } \\
\text { Not broken }\end{array}$ & Pearson chi square & $P$ value \\
\hline \multicolumn{5}{|l|}{ AGE } \\
\hline $21-30$ & 0 & 12 & \multirow{5}{*}{17.71} & \multirow{5}{*}{$0.001 *$} \\
\hline $31-40$ & 1 & 42 & & \\
\hline $41-50$ & 2 & 112 & & \\
\hline $51-60$ & 18 & 114 & & \\
\hline $61-70$ & 8 & 46 & & \\
\hline \multicolumn{5}{|l|}{ GENDER: } \\
\hline MALES & 21 & 185 & \multirow{2}{*}{2.68} & \multirow{2}{*}{0.101} \\
\hline FEMALES & 8 & 141 & & \\
\hline
\end{tabular}

(*statistically significant)

Figure 2. Bar graph shows the gender distribution of patients with complete edentulism. X axis - gender(male/female) ; $\mathrm{Y}$ axis - number of patients with complete edentulism. The higher prevalence of complete edentulism was found among males. $(58.03 \%)$

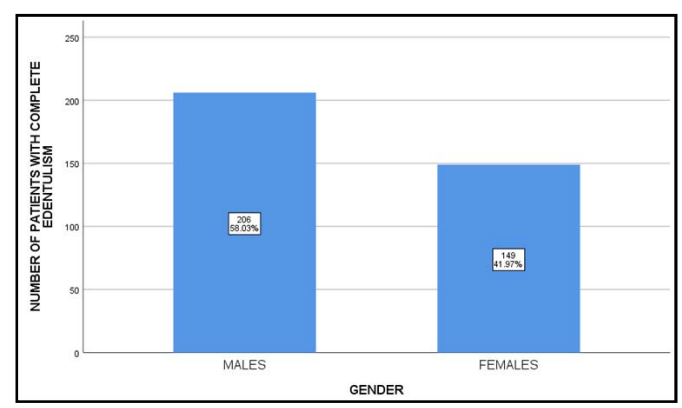

Figure 3. Bar graph shows the association between the status of denture and different age groups. $\mathrm{X}$ axis - age in years ; $\mathrm{Y}$ axis - number of patients with complete edentulism. The higher prevalence of broken dentures (green) was seen among the 51-60 years age group (5.07\%). There was statistically significant association between the status of denture and the age. Pearson Chi square value:17.717a ; p value- $0.001(\mathrm{p}<0.05)$, statistically significant.

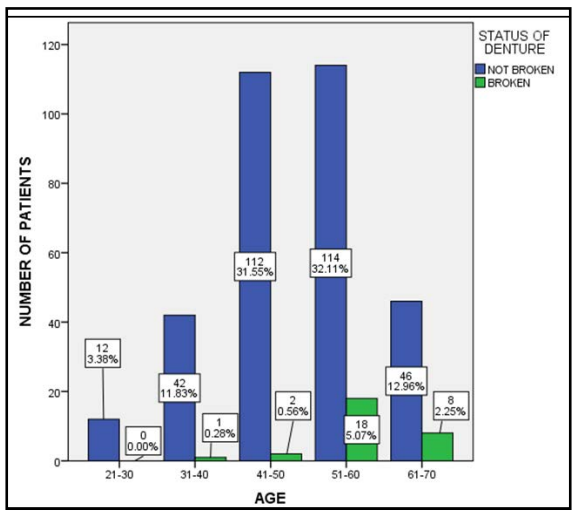

age group is $51-60$ years. The prevalence of broken denture is more common in males and less in females. There is a positive correlation in between the broken denture and the different age groups.

In the present study, there was a higher prevalence of broken denture among males. Previous studies have said that the more prevalence of broken dentures among males could be due to increased masticatory force and fatigue of the denture, this is in acceptance to our study, where there is a male predominance $(6.40 \%)[5,27$, 28]. There is association of biting force and the fracture of the denture. Among the young old aged patients, they are recent denture wearers, where there is increased biting force which leads to fracture of the denture. Study done by Sampa Ray 1 et.al, he said there is denture fracture due to increased biting force [27]. Studies done by Beley,et.al Hargreaves A.S, et.al, has said that the cause of the denture can either be mechanical or accidental [10, 29].

In the present study, the prevalence of broken dentures were higher among 51 to 60 years age groups followed by 61 to 70 year age groups. The prevalence among old aged people could be due to longer denture usage and also could be due to improper handling and hygiene maintenance among the patients. Previous studies have reported that the prevalence of broken dentures were more prevalent above 80 years age followed by 40 to 50 years age groups [30]. The reason for the variation in prevalence of broken dentures could be due to the geographic location, denture maintenance and the duration of denture wearing by the patient.

Denture fractures can be prevented by patient education on den- 
Figure 4. Bar graph shows the association between status of denture and gender. $\mathrm{X}$ axis - gender(males/females) ; $\mathrm{Y}$ axis - number of patients with complete edentulism. The higher prevalence of broken denture (green) was found among males $(5.92 \%)$ than females $(2.25 \%)$. There was no statistically significant association between the status of denture and the gender. Pearson Chi square value : 2.683 ; $p$ value- $0.101,(p>0.05)$ which was statistically not significant.

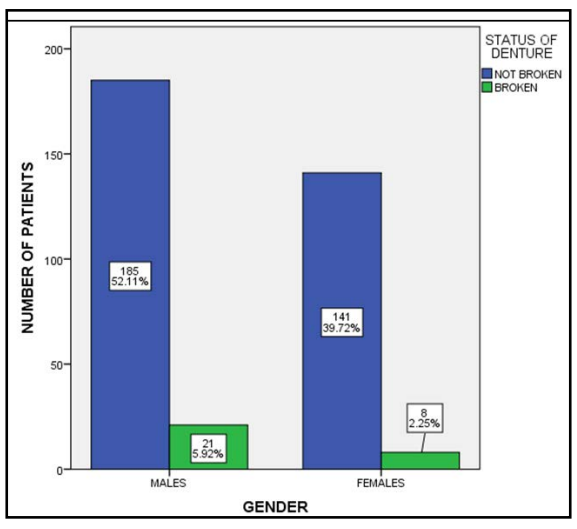

ture maintenance and oral hygiene maintenance and motivation to change the denture incase of any fracture or breakage. The case selection and the appropriate treatment planning are important for the delivery of the denture to the edentulous patients.

Recent advances such as use of a BPS denture base and CAD CAM milling dentures are commonly preferred in the clinical practice for the construction of complete denture [31-33]. The lucitone , metal base and modified acrylic denture bases can be used as an alternative due to their increased mechanical property [34]. The effect of practicing BPS dentures (modification of processing), by injection molding technique records the area more accurately which aids in the retention and stability of the denture. The use of $\mathrm{T}$ scan for bite force evaluation and occlusal equilibrium can be used to assess the masticatory efficiency of the individual and construct the denture accordingly [35]. All the above factors along with definite dental prosthetic principles should be taken into consideration for denture construction.

The limitation of the present study was that it was a retrospective study where we used data from the online digital case records. The prevalence of broken denture was evaluated from the patient's history which were recorded in the case records of the patients. To reduce the subjective variation, the case records were analysed by a single calibrated examiner. Records did not contain the history on the type, duration and cause of the fracture of the denture which could have been a profound factor in our study.

\section{Conclusion}

Within the limitation of the present study there was a male predominance of broken denture which can be due to high masticatory load. Secondly, completely edentulous old aged patients reported with breakage indicating long term use. On the other hand, for young aged completely edentulous patients, denture breakage chances were seen due to high masticatory forces following recent extractions. Hence forth change of new denture is recommended for the patients after a period of time and development towards denture material and technique is a need.

\section{Authors Contribution}

Prashaanthi. N contributed acquisition of data, analysis, literature collection and also in drafting the article and revising it critically for important intellectual content. Jessy .P and Subhabrata Maiti contributed in conception, the study design, interpretation of data, formatting, manuscript preparation, supervision and guidance. Shantha sundari. K.K contributed in editing, supervision and final approval of the submitted version of the manuscript.

\section{Acknowledgement}

We take pleasure to acknowledge our University for granting permission to utilize the patient records for data collection.

\section{References}

[1]. McCord JF, Grant AA. Identification of complete denture problems: a summary. Br Dent J. 2000 Aug 12;189(3):128-34.Pubmed PMID: 11041628.

[2]. Takamiya AS, Monteiro DR, Marra J, Compagnoni MA, Barbosa DB. Complete denture wearing and fractures among edentulous patients treated in university clinics. Gerodontology. 2012 Jun;29(2):e728-34.Pubmed PMID: 21883425

[3]. Vallittu PK, Lassila VP, Lappalainen R. Evaluation of damage to removable dentures in two cities in Finland. Acta Odontol Scand. 1993 Dec;51(6):3639.Pubmed PMID: 8304013.

[4]. Darbar UR, Huggett R, Harrison A. Denture fracture--a survey. Br Dent J. 1994 May; $176(9): 342-5$

[5]. Smith DC. The acrylic denture mechanical evaluation mid-line fracture. Br. Dent. J.. 1961;110:257-67.

[6]. Moraru AM, Preoteasa CT, Preoteasa E. Masticatory function parameters in patients with removable dental prosthesis. J Med Life. 2019 Jan;12(1):43-8.

[7]. Liedberg B, Ekberg O, Owall B. Chewing and the dimension of the pharyngoesophageal segment. Dysphagia. 1991;6(4):214-8.Pubmed PMID: 1778099 .

[8]. Woda A, Hennequin M, Peyron MA. Mastication in humans: finding a rationale. J Oral Rehabil. 2011 Oct;38(10):781-4.Pubmed PMID: 22093138.

[9]. Fontijn-Tekamp FA, Slagter AP, Van Der Bilt A, Van 'T Hof MA, Witter DJ, Kalk W, et al. Biting and chewing in overdentures, full dentures, and natural dentitions. J Dent Res. 2000 Jul;79(7):1519-24.Pubmed PMID: 11005738.

[10]. Beyli MS, von Fraunhofer JA. An analysis of causes of fracture of acrylic resin dentures. J Prosthet Dent. 1981 Sep;46(3):238-41.Pubmed PMID: 7021802.

[11]. Shala K, Tmava-Dragusha A, Dula L, Pustina-Krasniqi T, Bicaj T, Ahmedi E, et al. Evaluation of Maximum Bite Force in Patients with Complete Dentures. Open Access Maced J Med Sci. 2018 Mar 13;6(3):559-563.Pubmed PMID: 29610620.

[12]. Ashok V, Suvitha S. Awareness of all ceramic restoration in rural population. Res J Pharm Technol. 2016;9(10):1691-3.

[13]. Vijayalakshmi B, Ganapathy D. Medical management of cellulitis. Res J Pharm Technol. 2016;9(11):2067-70.

[14]. Basha FYS, Ganapathy D. Oral Hygiene Status among Pregnant Women. Res J Pharm Technol. 2018.

[15]. Jyothi S, Robin PK, Ganapathy D. Periodontal health status of three different groups wearing temporary partial denture. Res J Pharm Technol. 
2017;10(12):4339-42.

[16]. Duraisamy R, Krishnan CS, Ramasubramanian H, Sampathkumar J, Mariappan S, Navarasampatti Sivaprakasam A. Compatibility of Nonoriginal Abutments With Implants: Evaluation of Microgap at the Implant-Abutment Interface, With Original and Nonoriginal Abutments. Implant Dent. 2019 Jun;28(3):289-295.Pubmed PMID: 31124826.

[17]. Ganapathy D, Sathyamoorthy A, Ranganathan H, Murthykumar K. Effect of Resin Bonded Luting Agents Influencing Marginal Discrepancy in All Ceramic Complete Veneer Crowns. J Clin Diagn Res. 2016 Dec;10(12):ZC67ZC70.Pubmed PMID: 28209008.

[18]. Ranganathan H, Ganapathy DM, Jain AR. Cervical and Incisal Marginal Discrepancy in Ceramic Laminate Veneering Materials: A SEM Analysis. Contemp Clin Dent. 2017 Apr-Jun;8(2):272-278.Pubmed PMID: 28839415.

[19]. Venugopalan S, Ariga P, Aggarwal P, Viswanath A. Magnetically retained silicone facial prosthesis. Niger J Clin Pract. 2014 Mar-Apr;17(2):260-4. Pubmed PMID: 24553044

[20]. Ajay R, Suma K, Ali SA, Kumar Sivakumar JS, Rakshagan V, Devaki V, et al. Effect of Surface Modifications on the Retention of Cement-retained Implant Crowns under Fatigue Loads: An In vitro Study. J Pharm Bioallied Sci. 2017 Nov;9(Suppl 1):S154-S160.Pubmed PMID: 29284956.

[21]. Jain AR, Nallaswamy D, Ariga P, Ganapathy DM. Determination of correlation of width of maxillary anterior teeth using extraoral and intraoral factors in Indian population: A systematic review. World J Dent. 2018 Jan;9:68-75.

[22]. Ashok V, Nallaswamy D, Benazir Begum S, Nesappan T. Lip Bumper Prosthesis for an Acromegaly Patient: A Clinical Report. J Indian Prosthodont Soc. 2014 Dec;14(Suppl 1):279-82.Pubmed PMID: 26199531.

[23]. Selvan SR, Ganapathy D. Efficacy of fifth generation cephalosporins against methicillin-resistant Staphylococcus aureus-A review. Res J Pharm Technol. 2016;9(10):1815-8.

[24]. Subasree S, Murthykumar K. Effect of Aloe Vera in Oral Health-A Review.
Res J Pharm Technol. 2016;9(5):609-12.

[25]. Kannan A. Effect of Coated Surfaces influencing Screw Loosening in Implants: A Systematic Review and Meta-analysis. World. 2017 Nov;8(6):496502.

[26]. Kannan A, Venugopalan S. A systematic review on the effect of use of impregnated retraction cords on gingiva. Res J Pharm Technol. 2018;11(5):2121-6.

[27]. Ray PK, Makhal M, Sen SK. Incidence and causes of fracture of acrylic resin complete denture. J. Evol. Med. Dent. Sci. 2014 Dec 11;3(69):14787-94.

[28]. Broz M, Omrcen A, Ropac D. Characteristics of fractures in complete dentures. Vojnosanit Pregl. 1991 Jan 1;48(1):46-50.

[29]. Hargreaves AS. The prevalence of fractured dentures. A survey. Br Dent J. 1969 May 20;126(10):451-5.

[30]. Bosânceanu DN, Beldiman A, Baciu RE, Bolat M, Bosânceanu DG, Forna NC. Complete dentures fractures-causes and incidence. J. Oral Rehabil. 2017 Jan;9(1).

[31]. Saini V, Singla R. Biofunctional prosthetic system: A new era complete denture. J Pharm Bioallied Sci. 2011 Jan;3(1):170-2.Pubmed PMID: 21430969.

[32]. John AV, Abraham G, Alias A. Two-visit CAD/CAM milled dentures in the rehabilitation of edentulous arches: A case series. J Indian Prosthodont Soc. 2019 Jan-Mar; 19(1):88-92.Pubmed PMID: 30745760.

[33]. Han W, Li Y, Zhang Y. Design and fabrication of complete dentures using CAD/CAM technology. Medicine. 2017 Jan;96(1): e5435.

[34]. Phukela SS, Chintalapudi SK, Sachdeva H, Dhall RS, Sharma N, Prabhu A. Comparative evaluation of different mechanical modifications of denture teeth on bond strength between high-impact acrylic resin and denture teeth: An in vitro study. J Int Soc Prev Community Dent. 2016 MarApr;6(2):161-6.Pubmed PMID: 27114957.

[35]. Agbaje JO, Casteele EV, Salem AS, Anumendem D, Shaheen E, Sun Y, et al. Assessment of occlusion with the T-Scan system in patients undergoing orthognathic surgery. Sci Rep. 2017 Jul 13;7(1):1-8.Pubmed PMID: 28706294. 